\title{
ACOUSTIC REFLEX MEASUREMENTS AND THE LOUDNESS FUNCTION IN SENSORINEURAL HEARING LOSS
}

\author{
SHEILA ULIEL, M.A. (AUDIOLOGY) (WITWATERSRAND) \\ Unit for Hearing-impaired Children, University of the Witwatersrand, Johannesburg.
}

\section{SUMMARY}

The suprathreshold acoustic reflex responses of forty two ears affected by sensorineural hearing loss of cochlear origin and fifty-eight ears demonstrating normal hearing, were recorded by means of an clectro-acoustic impedance meter and attached X-Y recorder. The recordings were done in ascending and descending fashion, at successively increasing and decreasing $5 \mathrm{~dB}$ intensity levels from 90-120-90 dB HL respectively, for the individual pure-tone frequencics of $500,1000,2000$ and $4000 \mathrm{~Hz}$. The contralateral mode of measurement was employed.

Analysis of these recordings indicated that the acoustic reflex responses could be differentiated into five characteristic patterns of growth, which could be depicted upon a continuum of peaked, peaked-rounded, rounded, rounded-flat, and flat shapes.

The peaked and peaked-rounded patterns were found to predominate at all four pure-tone frequencies in the normal ears, while the rounded-flat and flat patterns were found to predominate only at the higher pure-tone frequencies of 2000 and $4000 \mathrm{~Hz}$ in the cars affected by sensorineural hearing loss. This latter relationship was also able to be applied to two disorders of the loudness function - loudness recruitment and hyperacusis.

It was concluded that the flattened acoustic reflex patterns at the higher pure-tone frequencies constituted a potential diagnostic cue related to the differential diagnosis of sensori-neural hearing loss, and to disorders of the loudness function.

\section{OPSOMMING}

Die bo-drumpel akoestiese refleks responsies van twee-en-veertig ore wat aangetas is deur sensori-nervale hoorverlies van cochlear oorsprong, en agt-en-vyftig ore met normale gehoor, is deur 'n clcktro-akoestiese impedansmeter en angehegtc X-Y opnemer vasgelê. Die opnemings is in stygende en dalende wyse, teen opeenvolgende toenemende en afnemende $5 \mathrm{~dB}$ intensiteitvlakke van 90-120-90 dB elk, vir die afsonderlike suiwerklank frekwensies van $500,1000,2000 \mathrm{cn} 4000 \mathrm{~Hz}$ gemaak.

Ontleding van hierdic opmetings bewys dat die akoestiese refleks responsics in vyf karakteristieke groeipatrone gedeel kan word. Die grocipatrone kan weergegee word op 'n kontinuüm van puntig, puntig-gerond, gerond, gerond-plat en plat vorms. Dic puntig en puntig-geronde patrone is oorheersend gevind teen alle vier van die suiwerklank frekwensies in die normalc ore, terwyl die gerond-plat en plat patrone slegs teen die hoër frekwensies van 2000 en $4000 \mathrm{~Hz}$ in dic orc aangetas deur sensori-nervale gehoorverlies oorhecrsend was. Hierdie laasgenoemde verwantskap kan ook tocgepas word op twee afwykings van die geluidskrag funksic - geluidheidsopbou en hiperakusie. Die gevolgtrekking is afgelei dat die plat akoestiese reflekspatrone teen dic hoër suiwerklank frekwensies as 'n potensiële leidraad kan dien, verwant aan die differensiële diagnose van sensori-nervale hoorverlies en afwykings van die geluidskrag funksic.

In recent years, there has been considerable discussion of a variety of suprathreshold auditory measures which have been used for both diagnostic and rehabilitative evaluations of patients with sensorineural hearing losses.

According to Stephens et al ${ }^{19}$ a limited dynamic range of hearing, is in fact, the demonstration of 'loudness recruitment', which is traditionally 
used to indicate . . a more-rapid-than-normal increase in subjective loudness for a given increase in physical intensity, (Hirsch et al, p. 213). ${ }^{9}$ Loudness recruitment has been conventionally accepted as being of great clinical value in pinpointing the locus of the sensorineural impairment. Dix et $\mathrm{al}^{8}$ were the first investigators to claim that the presence or absence of loudness recruitment would differentiate cochlear from retrocochlear pathologies, respectively. Following on from their work, various procedures, both direct and indirect, were developed to determine the presence of loudness recruitment in the clinical situation. Serious limitations have been noted with all the loudness recruitment procedures, with the exception of the Metz Recruitment test, developed in 1952. This test, which is considered to be both a direct and objective procedure, employs, as its basis, the fundamental principle of measuring changes in acoustic impedance at the eardrum, caused by the contraction of the acoustic (stapedius) reflex in response to sound.

The acoustic reflex threshold is considered to be the most basic, static characteristic of the acoustic reflex (Petersen and Liden), ${ }^{16}$ and it describes the sensitivity of the fundamental acoustic reflex stimulusresponse function. It has been thoroughly investigated, and is currently well understood and extensively applied to clinical audiological diagnosis. For example, cochlear diagnosis utilises the narrowed relationship between the acoustic reflex threshold and the lowered audiometric threshold in the establishment of inner ear dysfunction and disordered loudness growth (or loudness recruitment) (Metz) ${ }^{12}$ The dynamic properties of the acoustic reflex, which incorporate aspects of its response beyond threshold, have been the concern of investigators such as Borg ${ }^{4}$ and Møller ${ }^{13,14}$ It is their contention that the suprathreshold growth of the acoustic reflex response amplitude in the auditory frequency - and temporal - domains, and the interrelationship between this behaviour and different sound intensities, represents an important aspect of the dynamic behaviour of the acoustic reflex, which has not as yet been systematically applied to the clinical field.

Retrocochlear diagnosis utilises the dynamic temporal response characteristics of the acoustic reflex, in that an abnormally rapid decay of the acoustic reflex to prolonged suprathreshold stimulation is indicative of auditory nerve dysfunction (Anderson et $\mathrm{al}^{1,2}$; Sheehy and $\operatorname{Inzer}^{18}$ ). Cochlear diagnosis, however, does not utilise any of the knowledge gained from an understanding of the dynamic properties of the acoustic reflex, and relies exclusively upon examination of its static characteristics.

It would appear that the amplitude regulation of the acoustic reflex, within the auditory frequency-domain, can offer much to the establishment of cochlear sensori-neural hearing loss diagnosis. ${ }^{4,7,13,14,16}$ The cochlear is involved with the analysis of the frequency and intensity characteristics of sound (resulting in the perception of pitch and 
loudness), and disorders of the cochlear function interfere both with the hearing of certain frequencies (hearing loss), and with the loudness function (loudness recruitment). The acoustic reflex threshold has been shown to be related to the perception of loudness, ${ }^{3,5,6,11,17}$ but the relationship of its supra-threshold response characteristics to loudness perception requires detailed investigation.

Considerable variations in the growth of the acoustic reflex response amplitude to intensity have been noted, both with normal hearing, and with sensori-neural hearing loss, but as the precise significance of these variations has not yet been established, they appear to be generally attributable to individual differences (McCandless ${ }^{15}$ ). Furthermore, the influence of different sound frequencies upon the acoustic reflex amplitude growth has not been investigated, either in normal or pathological ears. No detailed description or classification of the types of acoustic reflex amplitude growth patterns exists, although a 'flattening' effect has been shown to occur with sensorineural hearing loss, which is exaggerated by the concomitant presence of loudness recruitment (Beedle and Harford ${ }^{3}$ ).

The present investigation aims at establishing if any variations in the acoustic reflex amplitude response, other than the 'flattening' effect, exist, which may be able to be differentiated and classified. Furthermore, this investigation attempts to examine the relationship between the acoustic reflex growth and several variables such as the frequency and intensity of the stimulus; the presence of absence of hearing loss; the presence or absence of cochlear pathology; and the presence or absence of loudness function disorders.

It is hoped that if differential acoustic reflex growth patterns are forthcoming, and that if these are significantly related to different pure-tones in normal hearing and cochlear sensori-neural hearing loss, and influenced by disorders of the loudness function, then an additional diagnostic cue regarding such disorders will be apparent. The writer anticipates that more sophisticated and accurate measurements of the dynamic response characteristics of the acoustic reflex will not only add to the body of knowledge about the acoustic reflex, but will also add to the diagnostic and rehabilitative acumen of the clinical audiologist.

\section{METHODOLOGY}

AIMS

To investigate the variations in the suprathreshold amplitude growth of the acoustic reflex, for different pure-tones, in normal hearing and in sensori-neural hearing loss, for the purposes of:

1. specifically characterising any differential acoustic reflex amplitude growth patterns or trends;

2. examining whether any such trends are related to different pure-tone frequencies; 
3. analysing whether the acoustic reflex amplitude growth is differentially related to normal hearing and-sensori-neural hearing loss;

4. analysing whether the acoustic reflex amplitude growth is in any way influenced by disorders of the loudness function.

\section{SUBJECTS}

Fifty subjects were selected to participate in the experiment, their ages ranging from 15 to 53 years, with a mean age of 32,8 years. These age limits were imposed in order both to ensure sufficient maturity for co-operation throughout the testing, and to avoid any contaminating effects of the ageing process upon hearing and the behaviour of the acoustic reflex. Both sexes were represented in that 24 males and 26 females were selected.

From the 50 subjects selected, an experimental group (EG) and a control group (CG) were derived, the former comprising 42 ears with cochlear sensori-neural hearing loss; the latter comprising 52 ears with normal hearing. The hearing, in each case, was assessed according to specific predetermined criteria, which were established from an extensive assessment including a battery of audiological tests as follows:

\section{(1) Case History Details}

Each patient was carefully questioned with regard to any present or past difficulties with hearing; ear pathology; ear surgery; tinnitus, vertigo, headaches, problems with balance.

\section{(2) Otoscopic Examination}

This was carried out by an Ear, Nose and Throat specialist prior to the administration of the audiological test battery.

(3) Audiological Test Battery:

The following procedures were employed:

A. Testing of the bilateral hearing function, by establishing:

(i) Pure-tone air and bone conduction thresholds.

(ii) Speech reception thresholds.

(iii) Speech discrimination scores.

B. Assessment of the bilateral middle ear function, by means of:

(i) Tympanometry.

(ii) Calculation of the absolute acoustic impedance value at the plane of the eardrum.

(iii) Establishment of the acoustic reflex thresholds.

C. Differential diagnostic assessment of the site-of-lesion, incorporating an evaluation of the loudness function, including:

(i) ABLB Test 
(ii) SISI Test

(iii) Metz Recruitment Test

(iv) Carhart Tone Decay Test

(v) Acoustic Reflex Decay Test.

Table I summarises the criteria differentiating the subjects selected into the EG and the CG.

TABLE 1: Summary of the Criteria for Subject Selection, Differentiating them into $E G$ and $C G$

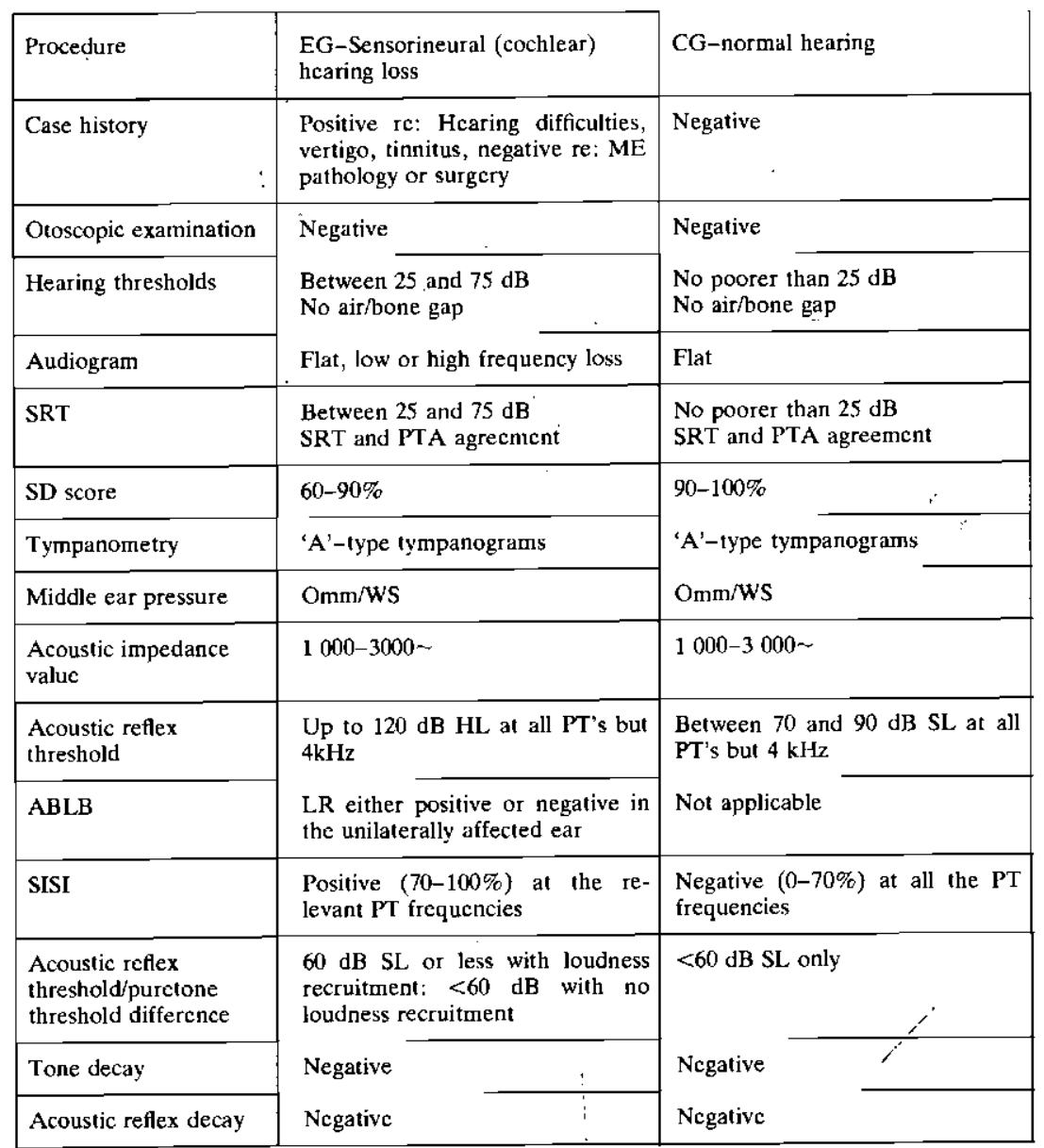

EQUIPMENT

All the tests were conducted with the subject seated in a single-suite sound-attenuating booth, where the ambient noise-level measured was not more than 36,7 dB SPL, recorded on the ' $\mathrm{C}$ ' scale of the Bruel and 
Kjaer (Type 2203) precision sound level meter, with condensor microphone (Model 4131).

The Maico 24 dual-channel diagnostic audiometer, with attached TDH 39-102 earphones and MX/AR cushions was used. Immediately prior to the commencement of the testing, the equipment was calibrated re: ISO 1964 standards, using the Bruel and Kjaer sound-level meter, with filter 1613 and artificial ear 4152/4145.

The Danplex Electro-acoustic Impedance Meter (Model ZA20) with attached TDH 39 earphone and standard (Madsen) clinical rubber tips on the probe-unit was used. This was calibrated re: ANSI 1971 standards, and the calibration was checked prior to each testing session by means of the 1 c.c. coupler provided.

The Minigor X-Y recorder, supplied with strip-chart cards and blue pen-marker, was connected to the impedance meter. The equipment was modified in terms of the insertion of an automatic timer, which was activated simultaneously with the pure-tone stimulus generator. The timer was set to produce a pure-tone stimulus of approximately 2 secs., (recorded as exactly 1,90 secs. within $5 \%$ - refer to Fig. 1), with intervals of 8 secs. between each stimulus-pulse. This 10 secs. timing interval was accordingly translated on to the demarcated strip-chart card in terms of 10 secs. per $1 \mathrm{~cm}$., along the abscissa (refer to Fig. 2). Also along the abscissa, the ascending and descending intensity levels, in $\mathrm{dB}$, were marked, with each intensity step corresponding to each $10 \mathrm{sec}$. timing interval.

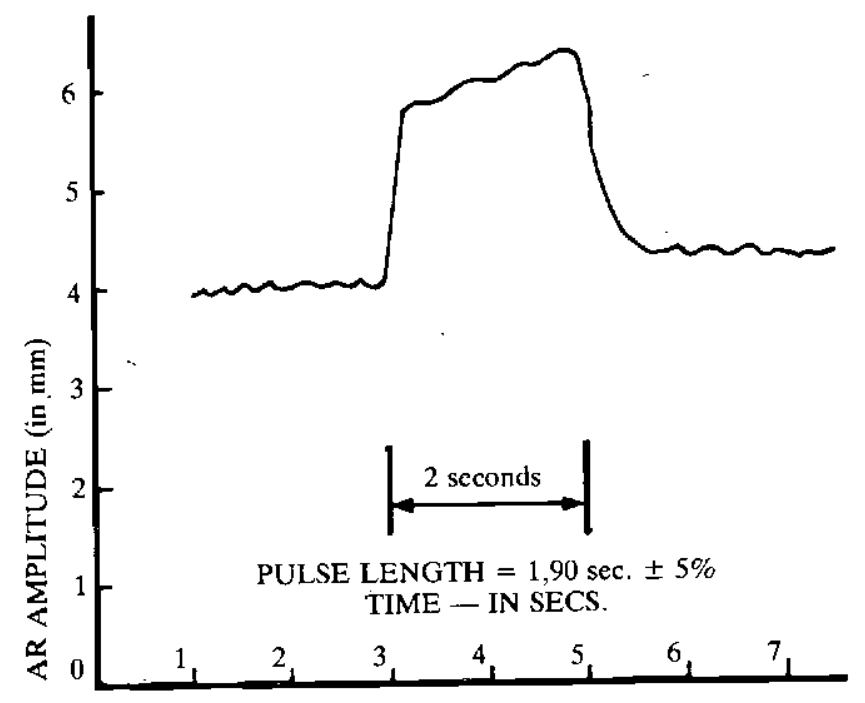

Figure 1. Example of an acoustic reflex response to a two second stimulus pulse

Die Suid-Afrikaanse Tydskrif vir Kommunikasieafwykings, Vol. 27, 1980 


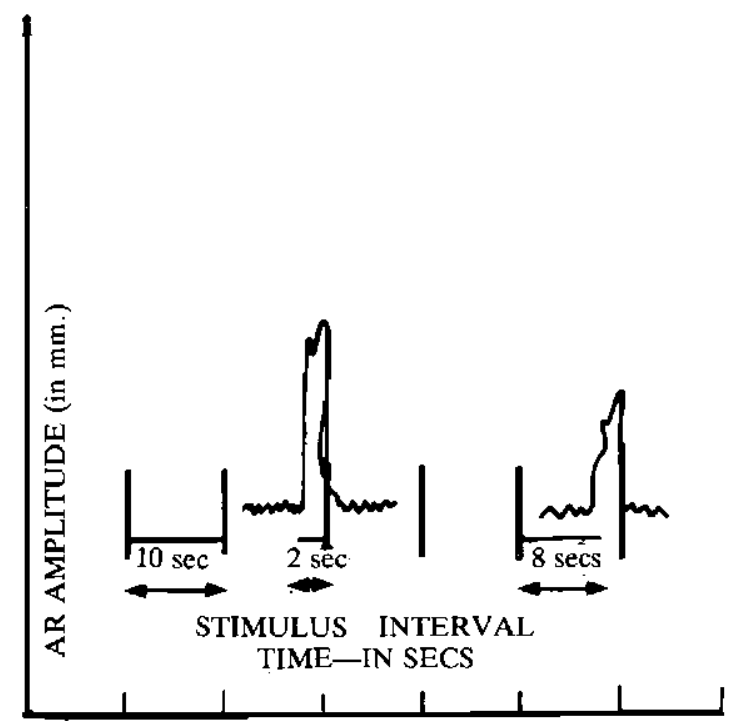

Figure 2. Representation of the time base in seconds $(10 \mathrm{sec} / \mathrm{cm})$.

Along the ordinate, the magnitudes of the acoustic reflex responses were scaled according to $20 \mathrm{mV}=1,0 \mathrm{cc}$ with the Impedance meter set at Sensitivity 2, and the X-Y recorder set to $\mathrm{mV} / \mathrm{cm}$., (refer to Fig. 3): In this manner, a bar diagram was obtained representing the recording of:

(i) each 2 sec. stimulus-pulse across $1 / 5 \mathrm{~cm}$. on the $\mathrm{X}$-axis;

(ii) each $8 \mathrm{sec}$. interval between stimulus-pulses across $4 / 5 \mathrm{~cm}$. on the X-axis;

(iii) the systematically ascending and descending $5 \mathrm{~dB}$ intensity levels (90-120-90 dB), along the X-axis;

(iv) the maximum amplitude of each acoustic reflex response, represented according to the given scale of $1 \mathrm{mV}=0,05 \mathrm{~cm}$, along the $\mathrm{Y}$-axis.

Figure 3 provides an example of one such recording for $1000 \mathrm{~Hz}$ tone pulses, indicating the acoustic reflex amplitudes at each intensity level.

\section{EXPERIMENTAL PROCEDURE}

Each ear was individually tested via the contralateral mode of 'stimulus presentation. The acoustic reflex response elicited was automatically recorded.

The ear-order of testing was noted, as the ear-tested-first was randomised from subject to subject. This was done in order to eliminate any artefacts which might be introduced into the experiment by temporary threshold shifts (TTS) due to fatigue of the contralateral ear-tested-second, after having previously been exposed to prolonged stimulation. 


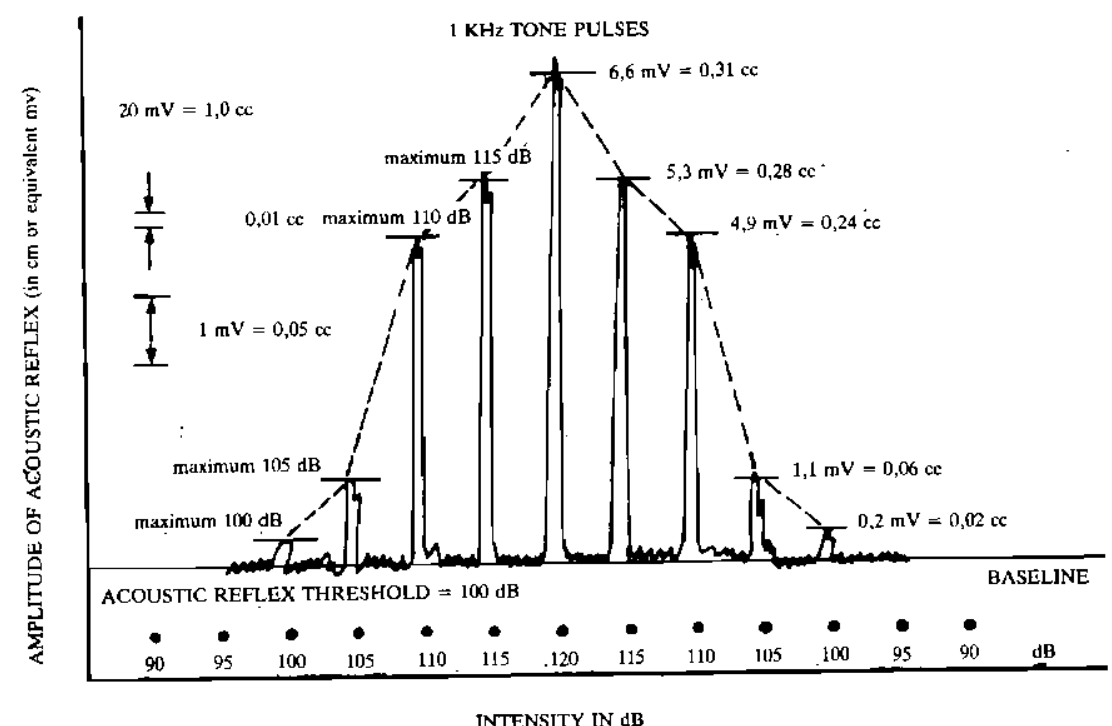

Figure 3. Example of the acoustic reflex amplitudes at different intensity levels for $100 \mathrm{~Hz}$ pure-tone stimulus pulses.

The subject was instructed to sit comfortably, and as motionlessly as possible, during the recording of each set of stimulus presentations, the duration of which involved a maximum period of 120 secs.

The pure-tone frequencies tested were $500,1000,2000$, and 4000 $\mathrm{Hz}$, in that order, for each ear. Each pure-tone frequency tested represented a single strip-chart card.

The minimum stimulus intensity level of presentation (starting and ending point) for each pure-tone frequency tested, was arbitrarily selected as $90 \mathrm{~dB}$; the maximum intensity level, beyond which point the descending presentation mode began, was $120 \mathrm{~dB}$. (This represented the maximum output level of the Impedance meter).

The test was begun by the investigator manually depressing the interruptor switch, which automatically put into operation the first 2 sec. stimulus-pulse (ie. $500 \mathrm{~Hz}$ at $90 \mathrm{~dB}$ ), followed by an $8 \mathrm{sec}$. interval. During the interval, the investigator manually raised the intensity level by $5 \mathrm{~dB}$ (ie. the dial was then set at $95 \mathrm{~dB}$ ), and again depressed the interruptor switch. In this way, 90-120 dB stimuluspulses were presented in ascending fashion, followed by $115-90 \mathrm{~dB}$ stimulus-pulses in descending fashion, for each pure-tone frequency, for each ear.

In this manner, 8 bar-diagrams per subject were obtained, representing the behaviour of the acoustic reflex amplitude response to systematically increasing and decreasing intensity levels, for four pure-tone frequencies, per ear, with a constantly maintained time interval. 
These bar-diagrams represented the raw data. At each pure-tone frequency, a pattern of acoustic reflex amplitude growth was able to be established by connecting the points of maximum amplitude for each individual acoustic reflex response recording over the ascending and descending 90-120-90 dB intensity levels. Examination of the acoustic reflex growth patterns (ARGP's), thus established, was done by the examiner, who subjectively and arbitrarily assigned a label to each pattern aimed at succinctly describing its shape.

Objective verification of the subjectively labelled patterns was then carried out. This was considered necessary, so that the individual results could be pooled, into a composite diagram reflecting the average pattern for each ARGP, which was done in the following manner: Firstly, each individual acoustic reflex response, at each intensity level, was measured (in $\mathrm{mm}$ ) and recorded on to computer coding sheets. Thirteen measures, per strip-chart card, were recorded, and a total of 104 such measures for each person was recorded.

Examinations of these measurements revealed that the scale of the ARGP's was highly variable between subjects, and a standardisation procedure, in order to arrive at a comparable scale between the numerous measurements was therefore, applied to each individual acoustic reflex response measure recorded. Thereafter, the standardised data was coded, and punched onto computer cards.

The IBM 360 computer at the University of the Witwatersrand was used, and the Statistical Package for the Social Sciences computer programme (Nie et al, 1975 . . . SPSSH version 6.00 for the University of the Witwatersrand, Johannesburg), was employed.

The statistical means of all the standardised measures, at each individual intensity, both for the ascending and for the descending presentations, for each pure-tone frequency, were computed. These averages were then processed, enabling them to be represented as computerised graphs. In this way, twenty different computerised average graphs were obtained, each representing a different ARGP, at each of the four pure-tone frequencies.

Following the establishment of the different ARGP's they were then analysed in detail with regard to their occurrences in normal hearing and sensorineural hearing loss, and with regard to their relationships to disorders of the loudness function. Relative percentage frequency distributions were used for intra- and inter-group comparisons, and the Chi-square test was used to test the significance of relationships between the groups.

\section{RESULTS AND DISCUSSION}

(1) ANALYSIS OF THE ACOUSTIC REFLEX RESPONSE

Five different ARGP's were able to be distinguished, both by subjective and objective means. The ARGP's appeared to lie upon a continuum as follows: 


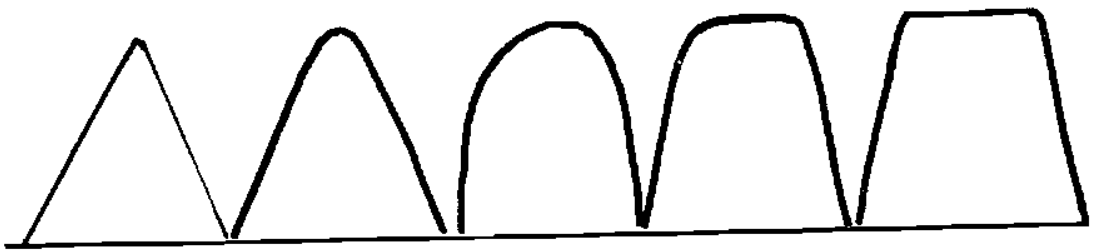

Figure 4. Diagrammatic representation of five different ARGP'S

Where no acoustic reflex response was triggered, despite maximumstimulation, (which occurred most frequently at $4000 \mathrm{~Hz}$ ), the label 'no growth' was assigned.

Table II illustrates the distribution of the ARGP's in the CG and EG while Table III compares the relative distributions of the ARGP, $s$ in the $C G$ and $E G$.

TABLE II: Frequency Distribution of ARGP's in the CG and EG

\begin{tabular}{|l|c|c|l|}
\hline \multicolumn{1}{|c|}{ Ears } & CG & EG & $\%$ Total \\
ARGP & & & \\
\hline Peaked & $29,5 \%$ & $8,5 \%$ & $38 \%$ \\
Rounded & $10,5 \%$ & $9,5 \%$ & $20 \%$ \\
Peaked-Rounded & $12,5 \%$ & $3,75 \%$ & $16,25 \%$ \\
Flat & $2,75 \%$ & $10,75 \%$ & $13,5 \%$ \\
Rounded-Flat & $0 \%$ & $7,25 \%$ & $7,25 \%$ \\
No Growth & $2,75 \%$ & $2,25 \%$ & $5 \%$ \\
\cline { 1 - 2 } Total & $58 \%$ & $42 \%$ & $100 \%$ \\
\hline
\end{tabular}

TABLE III: Relative \% Frequency Distribution of ARGP's in the CG and EG

\begin{tabular}{|l|c|c|}
\hline \multicolumn{1}{|c|}{ Ears } & CG & EG \\
ARGP & & \\
\hline Peaked & $51 \%$ & $20 \%$ \\
Rounded & $17,5 \%$ & $23,5 \%$ \\
Peaked-Rounded & $22 \%$ & $8 \%$ \\
Flat & $5 \%$ & $26,5 \%$ \\
Rounded-Flat & $0 \%$ & $17 \%$ \\
No Growth & $4,5 \%$ & $5 \%$ \\
\hline Total & $100 \%$ & $100 \%$ \\
\hline
\end{tabular}

In the CG, peaked patterns are seen to dominate (51\% of the time), while flat and rounded-flat patterns are minimally represented (5\% and $0 \%$, respectively).

Die Suid-Afrikaanse Tydskrif vir Kommunikasieafwykings, Vol. 27, 1980 
In the EG, although all but the peaked-rounded patterns have relatively similar statistical representation (ranging from 17 to 26,5\%), when comparing these percentages to the same pattern categories in the $\mathrm{CG}$, a distinct differentiation is observed. Flat and rounded-flat patterns occur with much greater frequency in the EG than in the CG; while peaked and peaked-rounded patterns occur with much greater frequency in the CG than in the EG. The rounded patterns and cases of 'no growth' are very similarly distributed, respectively, within the EG and CG.

The dichotomy of the two extremes on the ARGP continuum is clear, with the peaked and peaked-rounded extreme occurring most frequently in the $C G$, and the flat and rounded-flat extreme occurring most frequently in the EG.

The rounded patterns, form an intermediate link between the two extremes, in both groups, which are not significantly distinguishable as a single entity.

Table IV compares the relative distributions of the ARGP's with each pure-tone frequency between the EG and the CG.

TABLE IV: Relative \% Frequency Distribution of ARGP's at each Pure-Tone Frequency for $E G$ and $C G$

\begin{tabular}{|c|c|c|c|c|c|c|c|c|}
\hline & \multicolumn{8}{|c|}{$\%$ Frequency of Occurrence at } \\
\hline & \multicolumn{2}{|c|}{$500 \mathrm{~Hz}$} & \multicolumn{2}{|c|}{$1000 \mathrm{~Hz}$} & \multicolumn{2}{|c|}{$2000 \mathrm{~Hz}$} & \multicolumn{2}{|c|}{$4000 \mathrm{~Hz}$} \\
\hline & $\mathrm{CG}$ & EG & $\mathrm{CG}$ & EG & $\mathrm{CG}$ & EG & $\mathrm{CG}$ & EG \\
\hline Peaked & $56 \%$ & (46\% & 53\% & $1 \%$ & (46\%) & $13 \%$ & $41 \%$ & $11 \%$ \\
\hline Rounded & $16 \%$ & $2 \overline{6} \%$ & $15 \%$ & (31\% & $21 \%$ & $15 \%$ & $23 \%$ & $23 \%$ \\
\hline P/Rounded & $26 \%$ & $19 \%$ & $24 \%$ & $12 \%$ & $16 \%$ & $1 \%$ & $15 \%$ & $2 \%$ \\
\hline Flat & $2 \%$ & $0 \%$ & $8 \%$ & $29 \%$ & $5 \%$ & $38 \%$ & $5 \%$ & $32 \%$ \\
\hline R/Flat & $0 \%$ & $9 \%$ & $0 \%$ & $15 \%$ & $0 \%$ & $28 \%$ & $0 \%$ & $17 \%$ \\
\hline No Growth & $0 \%$ & $0 \%$ & $0 \%$ & $0 \%$ & $12 \%$ & $5 \%$ & $16 \%$ & $5 \%$ \\
\hline Total & $100 \%$ & $100 \%$ & $100 \%$ & $100 \%$ & $100 \%$ & $100 \%$ & $100 \%$ & $100 \%$ \\
\hline
\end{tabular}

From observations of the ringed figures in each pure-tone frequency column it is clear that:

At $500 \mathrm{~Hz}$ peaked patterns dominate in both groups'of Ss.

At $1000 \mathrm{~Hz}$ peaked patterns dominate in the CG, while rounded do so in the EG.

At $2000 \mathrm{~Hz}$ peaked patterns dominate in the $\mathrm{CG}$, while flat and rounded-flat occur most frequently in the $\mathrm{EG}$.

At $4000 \mathrm{~Hz}$ peaked patterns dominate in the CG, while flat do so in the EG.

From the above tables, it would appear that peaked patterns dominate in normal ears at all four pure-tone frequencies. With sensorineural 
hearing loss, the ARGP's are difficult to be 'typed' with the lower pure-tone frequencies of $500 \mathrm{~Hz}$ and $1000 \mathrm{~Hz}$, but the flat and rounded-flat patterns occur most frequently in this group at the higher pure-tone frequencies of 2000 and $4000 \mathrm{~Hz}$. The fact that a 'flattening' of the ARGP's occurs in the presence of sensorineural hearing loss is in agreement with the findings of Beedle and Harford ${ }^{3}$ who demonstrated an overall flattening of the acoustic reflex response in such cases.

The results of the present investigation, however, appear to indicate that the 'flattening' effect is pure-tone frequency specific, occurring predominantly with the higher pure-tone frequencies.

No growth occurs most frequently at $4000 \mathrm{~Hz}$ and not at all at the lower pure-tone frequencies. This is an expected result as acoustic reflexes are almost always readily demonstrable at the lower pure-tone frequencies, but often do not occur at all at the higher pure-tone frequencies, especially $4000 \mathrm{~Hz}$. Out of the total sample, the 'no growth' was shown $5 \%$ of the time, and this is in agreement with a previous study of Jerger et $\mathrm{al}^{10}$ who found that no acoustic refiex could be recorded at $4000 \mathrm{~Hz} 4-10 \%$ of the time, both in normal and abnormal hearing. The conclusions derived from the results of the Jerger et al ${ }^{10}$ study and from the present study, therefore, appear to indicate that $4000 \mathrm{~Hz}$ is at least qualitatively different from the other pure-tone frequencies with respect to its incidence of inexplicable absence of the acoustic reflex, both in normal hearing, and in sensorineural hearing loss. Jerger et al, however, do not accord the absence of acoustic reflex responses at $4000 \mathrm{~Hz}$ with any pathological significance.

With regard to the frequency range of 500 to $4000 \mathrm{~Hz}$, (including the $4 \mathrm{kHz}$ tone in the instances where an acoustic reflex is able to be demonstrated), however, the results of the present investigation show a significant frequency effect upon the ARGP's, which occur beyond threshold, in both normal and senorineural hearing loss, whereas the Jerger et al study showed no such frequency effect upon the acoustic reflex responses at threshold.

The writer takes cognisance of the fact that although both studies were concerned with measurement of the acoustic reflex response, the Jerger et $\mathrm{al}^{10}$ study was concerned with its response at threshold, while the present investigation is concerned with its response beyond threshold, and as such, a different phenomenon might well be implicated. According to Jerger et al, ${ }^{10}$ the lack of a frequency effect upon the acoustic reflex at threshold provides one of the most important norms of impedance audiometry for the practising clinician - ie. the maximum audiometric loss that a patient with sensorineural hearing loss can sustain before the acoustic reflex disappears at any or all of the pure-tone frequencies tested. This parameter has greatest value in lending support to audiometric thresholds established, especially in such cases where this is informally done by means of 
behavioural observations. The fact that there is a significant frequency effect upon the acoustic reflex response beyond threshold, may just as well provide an important future diagnostic sign for the practising clinician with regard to the differential diagnosis of the sensorineural hearing loss from normal hearing, in the acoustic reflex suprathreshold realm.

(2) ANALYSIS OF THE ARGP'S IN DISORDERS OF THE LOUDNESS FUNCTION

(i) Analysis of the ARGP's in sensorineural hearing loss with concomitant loudness recruitment (refer table V)

The differential diagnostic assessment of site-of-lesion, and the evaluation of the loudness function incorporated three procedures considered capable of demonstrating the presence or absence of loudness recruitment. Loudness recruitment was considered to be present in any ear if, at any single pure-tone frequency, the results of the ABLB, Metz Recruitment and SISI tests were positive - (with the ABLB results included where applicable).

TABLE V: The Frequency of Occurrence of Loudness Recruitment in the EG and CG.

\begin{tabular}{|l|c|c|c|}
\hline \multicolumn{1}{|c|}{ LR } & Present & Absent & Total \\
\cline { 1 - 1 } EG & $37(88 \%)$ & $5(12 \%)$ & $42(100 \%)$ \\
\hline CG & 0 & $58(100 \%)$ & $58(100 \%)$ \\
\hline Total & 37 & 63 & 100 \\
\hline
\end{tabular}

Loudness recruitment was not demonstrated in any of the 58 normal ears, forming the $\mathrm{CG}$.

Loudness recruitment was demonstrated in 37 out of the 42 ears having sensorineural hearing loss, constituting $88 \%$ of the EG. Only 5 ears which were affected by sensorineural hearing loss did not demonstrate loudness recruitment, constituting $12 \%$ of the EG. As such, nearly all of the results pertaining to the EG, with the exception of the 5 ears which did not demonstrate loudness recruitment, can be considered to be representative of the characteristic/ARGP in sensorineural hearing loss with loudness recruitment. Due to the extremely small sample size of the subgroup representing sensorineural hearing loss without loudness recruitment (ie. 5 ears), individual examination of the characteristics of these ears was carried out in order to see if they were consistently similar to or different from the results of the major EG. Depending upon the observations that were forthcoming, inferences regarding the EG, with the exclusion of these 5 ears (ie. sensorineural hearing loss with loudness recruitment 
only), were then able to be made, upon qualitative, if not upon quantitative grounds.

(ii) The analysis of the ARGP's in sensorineural hearing loss, without concomitant loudness recruitment

This is illustrated as follows:

TABLE VI: Frequency Distribution of the ARGP's at each Pure-Tone Frequency in EG, without Loudness Recruitment (5 Ears)

\begin{tabular}{|l|c|c|c|c|c|}
\hline \multirow{2}{*}{ ARGP } & \multicolumn{5}{|c|}{ Frequency of Occurrence at: } \\
\cline { 2 - 6 } & $500 \mathrm{~Hz}$ & $1000 \mathrm{~Hz}$ & $2000 \mathrm{~Hz}$ & $4000 \mathrm{~Hz}$ & Total \\
\hline Peaked & 5 & 3 & 4 & 4 & 16 \\
Rounded & 0 & 2 & 0 & 0 & 2 \\
P/Rounded & 0 & 0 & 1 & 0 & 1 \\
Flat & 0 & 0 & 0 & 0 & 0 \\
R/Flat & 0 & 0 & 0 & 0 & 0 \\
No Growth & 0 & 0 & 0 & 1 & 1 \\
\hline Total & 5 & 5 & 5 & 5 & 20 \\
\hline
\end{tabular}

It is clearly obvious that this small group of ears functions essentially like the $C G$, and not like the $E G$, in terms of the frequency distribution of the ARGP's. Peaked patterns are observed to dominate at all four pure-tone frequencies, while the rounded-flat and flat patterns have no representation whatsoever. This implies that the results of the EG, therefore, can be taken to be representative of the sensorineural hearing loss WITH loudness recruitment sub-group, as the small sub-group of sensorineural hearing loss WITHOUT loudness recruitment is shown to function in a consistently different manner, with regard to the ARGP's.

The ARGP responses in sensorineural hearing loss, in the presence of loudness recruitment, therefore, were shown to be predominantly rounded-flat and flat at the higher pure-tone frequencies of 2000 and $4000 \mathrm{~Hz}$.

The ARGP responses in sensorineural hearing loss, in the absence of loudness recruitment, on the other hand, were shown to be predominantly peaked at all pure-tone frequencies, which was the identical ARGP response obtained in normal hearing.

(iii) Analysis of the ARGP's in normal hearing with hyperacus 'Hyperacusis' is the term used by the investigator to describe increased sensitivity to very loud sounds occurring with normal hearing. As such, it is distinct from loudness recruitment, which describes an abnormal sensitivity to loudness because of cochlear pathology, resulting in sensorineural hearing loss. Although hyperacusis occurs in the presence of normal hearing, it is nevertheless a disorder of the loudness 
function, and has been reported to be a characteristic symptom of Bell's palsy, which also provides an example of disordered loudness function in the absence of a hearing loss (Zakrisson and Borg ${ }^{20}$ ).

The demonstration of hyperacusis was not anticipated prior to the actual recording of the acoustic reflex amplitude responses, and its specific investigation, therefore, was not included within the original scope of this study. However, the presence of hyperacusis was reported several times during the recordings of the acoustic reflex amplitude response, by several normally hearing subjects, who found the extremely loud pure-tone stimuli ( 115 and $120 \mathrm{~dB})$ most discomforting, and almost painful, despite the fact that no evidence of loudness recruitment as tested by the Metz Recruitment Test was demonstrated, and where the SISI scores of the same subjects were negative. Furthermore, observation of the recordings of the acoustic reflex amplitude response in the specific cases where increased loudness sensitivity was reported, indicated that the growth of these acoustic reflex amplitude responses was dramatically larger when compared to the other cases who did not report increased loudness sensitivity. Figures 5 and 6 illustrate the differences in acoustic reflex amplitude response growth between one subject who reported an increased sensitivity to loudness with normal hearing, and another subject, also with normal hearing, who did not experience this.

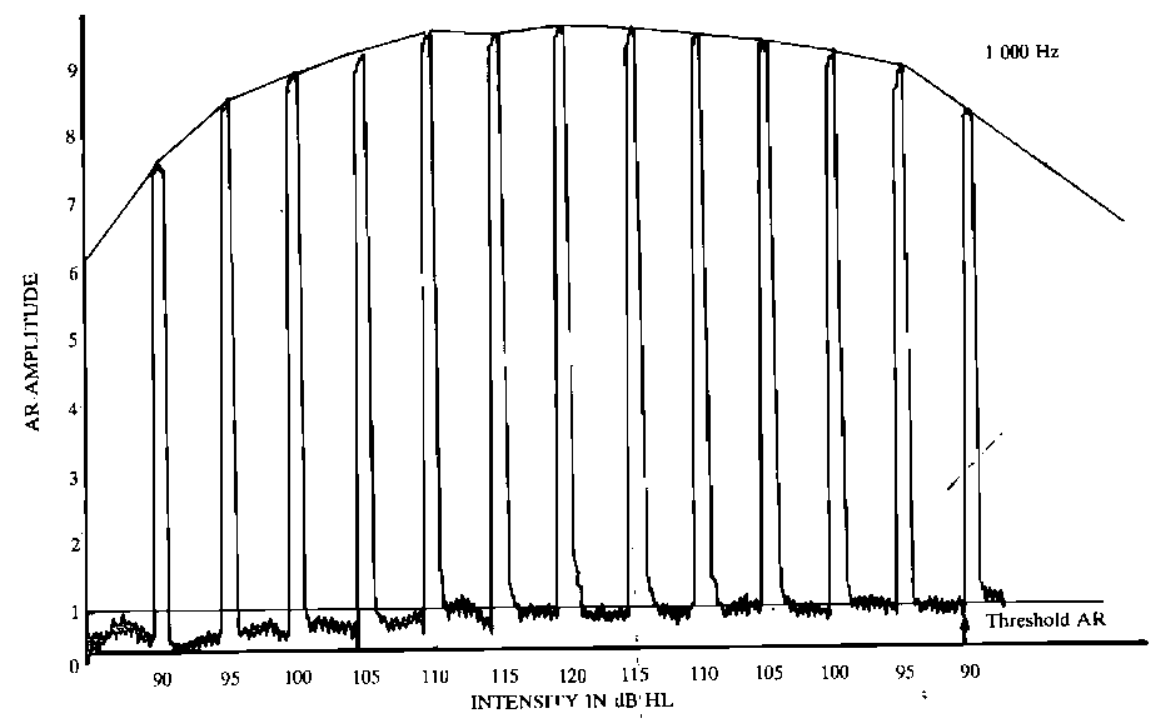

Figure 5. Example of acoustic reflex amplitude response growth in a case of normal hearing where hyperacusis was reported 


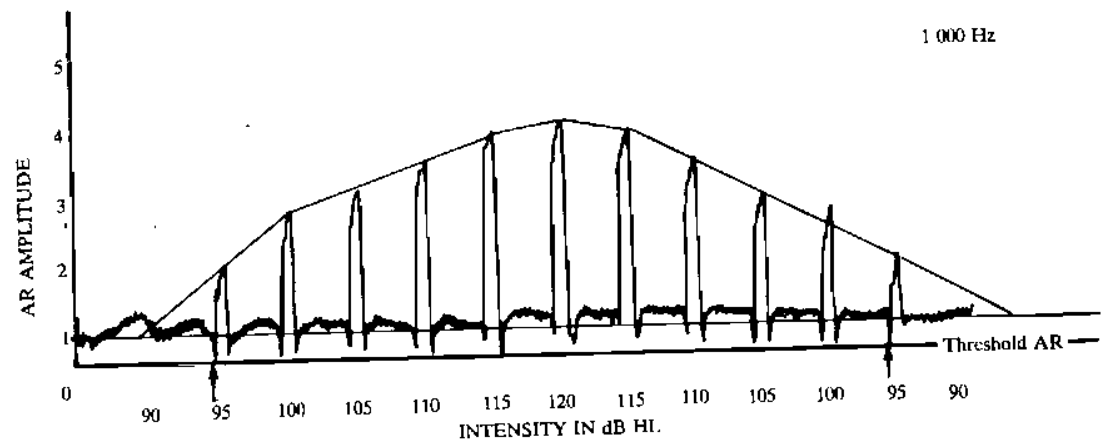

Figure 6. Example of acoustic reflex amplitude response growth in a case of normal hearing where hyperacusis was not reported

The fact that the phenomenon of hyperacusis was demonstrated so vividly led the investigator to consider its analysis warranted however superficial.

TABLE VII: The Frequency of Occurrence of Hyperacusis in the EG and CG

\begin{tabular}{|l|c|c|c|}
\hline \multicolumn{1}{|c|}{ Hyperacusis } & Present & Absent & Total \\
\hline EG & 0 & $42(100 \%)$ & $42(100 \%)$ \\
\hline CG & $15(8,5 \%)$ & $43(91,5 \%)$ & $58(100 \%)$ \\
\hline Total & 15 & 85 & 100 \\
\hline
\end{tabular}

Hyperacusis was not demonstrated in any of the 42 sensorineural ears, forming the EG. Hyperacusis was demonstrated in 15 out of the 58 normal ears, constituting $8,5 \%$ of the $\mathrm{CG}$.

TABLE VIII: The Distribution of the ARGP's at Each Pure-Tone Frequency for Hyperacusis in Normally Hearing Ears

\begin{tabular}{|l|c|c|c|c|c|}
\hline \multirow{2}{*}{ ARGP's } & \multicolumn{5}{|c|}{ Frequency of Occurrence at: } \\
\cline { 2 - 6 } & $500 \mathrm{~Hz}$ & $1000 \mathrm{~Hz}$ & $2000 \mathrm{~Hz}$ & $4000 \mathrm{~Hz}$ & Total \\
\hline Peaked & 0 & 0 & 0 & 0 & 0 \\
Rounded & 3 & 4 & 6 & 6 & 19 \\
P/Rounded & 0 & 0 & 0 & 0 & 0 \\
Flat & 1 & 2 & 8 & 12 & 23 \\
R/Flat & 0 & 0 & 8 & 10 & 18 \\
\hline Total & 4 & 6 & 22 & 28 & $60^{*}$ \\
\hline
\end{tabular}

*Note: The total is equal to 60, as any ARGP could occur in 15 ears at four pure-tone frequencies.

Die Suid-Afrikaanse Tydskrif vir Kommunikasieafwykings, Vol. 27, 1980 
The most significant finding here is that no peaked or peaked-rounded patterns occurred at all with hyperacusis, while rounded, rounded-flat and flat patterns occurred with relatively similar total frequency of occurrence, but noticeably more so at the higher than lower pure-tone frequencies. As such the ARGP's in the hyperacusis group appear to be able to be 'typed' in an identical manner to those of the subjects with sensorineural hearing loss with loudness recruitment, despite the fact that none of the normal hearing group demonstrated loudness recruitment on testing, by means of the traditionally accepted tests.

As such, the results of the analysis of the ARGP's in hyperacusis tend to imply that acoustic reflex response growth is more an indicator of disordered loudness function, than of sensorineural hearing loss, per se. This in turn implies that an assessment of disordered loudness function may be carried out, irrespective of the audiometric threshold, by assessing the acoustic reflex amplitude response in its suprathreshold realm.

\section{CONCLUSIONS}

Of the five acoustic reflex growth patterns which were established, two were able to be differentially related, by pure-tone frequency, to normal hearing and sensorineural hearing loss, as well as to disorders of the loudness function as follows:

Peaked patterns were observed predominantly at all four pure-tone frequencies in normal hearing or in sensorineural hearing loss WITHOUT concomitant loudness recruitment, while flat patterns were observed predominantly at the higher pure-tone frequencies of 2000 and $4000 \mathrm{~Hz}$ in sensorineural hearing loss with concomitant loudness recruitment, or in normal hearing with hyperacusis. In other words, the acoustic reflex response growth demonstrated a linear relationship to systematically increasing and decreasing intensity levels with normal loudness function, whereas it demonstrated an asymptotic (flattened) relationship to the same intensity levels with abnormal loudness function.

The writer concludes that the linear and asymptotic growth patterns of the suprathreshold acoustic reflex response, which respectively demonstrate the absence or presence of loudness dysfunction, are analogous to the well established linear and asymptotic loudness balance curves. The differential acoustic reflex growth patterns, therefore, appear to be able to be accorded with the same diagnostic significance as the differential loudness balance curves, and may be considered as complementary to the ABLB and MLB procedures, having the additional advantages of being quick and easy to administer, and relying upon objective and quantifiable responses. In cases where loudness balancing procedures are either not possible, or unsuccessful, as with very young children or with elderly people, the measurement of the suprathreshold acoustic reflex growth patterns is highly recommended. 
The dynamic properties of the acoustic reflex with regard to its amplitude regulation within the frequency-domain, therefore, appear to offer significant cues to the establishment of cochlear diagnosis, in the same way as its dynamic properties in the temporal-domain have been demonstrated to offer significant cues to the establishment of retrocochlear diagnosis. However, the writer wishes to emphasise that the measurement of the acoustic reflex response characteristics does not constitute a 'new' test of cochlear impairment and disordered loudness function. Rather, it represents another procedure in a series of tests which are based upon the same theoretical principles, and which appear to be illustrating the same basic pathological entity, ie. a selective destruction of the low-intensity elements in the organ of Corti (the outer hair cells) with the high-intensity elements (the inner hair cells) left intact to subserve the loudness function at high intensities.

The phenomenon of hyperacusis in normal hearing, might appear to confound the pathological entity described above, as there is no concomitant loss of hearing (which is the manifestation of the selective destruction of the low-intensity elements). However, the phenomenon of hyperacusis may be due, like some incipient retrocochlear disorders which do not manifest themselves in a hearing loss, to some type of malfunction beyond the level of the organ of Corti itself - ie. within the neural fibres or along the neural pathways, where no selective sparing of the low- or high-intensity elements occurs.

Apart from this intriguing theoretical speculation regarding the source of hyperacusis, the differential relationship of the acoustic reflex growth patterns to it, appears to be of considerable practical value in the clinical situation. Not only can the acoustic reflex growth patterns provide objective evidence of reported hyperacusis in some cases of facial nerve damage, but the same can be applied to the numerous reported incidences of hyperacusis among people with 'otherwise normal' hearing, who seek otological specialist opinion. Instead of the usual somewhat curt dismissal of the problem, or its appraisal as a manifestation of 'neuroticism' or an idiosyncratic personality trait, the objective demonstration of this reported subjective sensation might help to alleviate the frequent associated anxieties of hyperacusis, whereby it is interpreted (by the person who suffers from it) as being indicative of either impending 'deafness' or 'mental instability'.

The writer is well aware of the fact that these suggestions are proffered on the basis of the results found with only 15 ears, and recommends that further investigation of the phenomenon of hyperacusis be carried out, on larger sample sizes, before adopting the suggestions with any degree of confidence. Continuing in the same vein, the writer feels that hearing-aid users can also benefit from the objective evidence of their 'intolerance' to amplification, which might otherwise be construed by others as being 'obstinacy' as regards the use of a hearing-aid.

Finally, in conclusion, the writer takes cognisance of the fact that the flattened acoustic reflex growth patterns were restricted to the higher 
pure-tone frequencies. This may be entirely due to experimental design and the subject-selection procedures, which resulted in a sample of sensorineural hearing loss which was mainly restricted to these frequencies, with the exception of Meniere's Disease, where the hearing loss occurred mainly in the lower pure-tone frequencies. The number of cases of Meniere's Disease in this experiment, however, was not sufficiently large to be able to be subjected to any statistical analysis. Future research aimed at investigating the effects of predominantly low-frequency and predominantly high-frequency hearing losses upon the acoustic reflex growth patterns, therefore, is required. This would enable the determination of whether the specifically highfrequency flattened response of the acoustic reflex growth patterns is merely an artefact of the experimental design in this study, or whether it represents another theoretical issue, or characteristic aspect of the acoustic reflex response in the suprathreshold realm.

\section{REFERENCES}

1. Anderson, H., Barr, B., and Wedenberg, E. (1969): Intra-aural Reflexes in Retrocochlear Lesions. In: Disorders of the Skull Base Region, p. 49, Hamberger, C., and Wersäll, J. (Eds.), Almquist and Wiksell, Stockholm.

2. Anderson, H., Barr, B. and Wedenberg, E. (1970): Early Diagnosis of Eighth Nerve Disorders. Acta Otolaryngol., Suppl. 263: 232.

3. Beedle, R. K. and Harford, E. R. (1973): A Comparison of Acoustic Reflex and Loudness Growth in Normal and Pathological Ears. J. Speech Hear. Disord., 16: 271.

4. Borg, E. (1976): Dynamic characteristics of the intra-aural muscle reflex. In: Acoustic Impedance and Admittance: the Measurement of Middle Ear Function. Ch. 11, pp. 236-299. Wilber, L. and Feldman, A. (Eds.) The Williams \& Wilkins Co., Baltimore, USA

5. Chiveralls, K. and Fitzsimons, R. (1973): Stapedial Reflex Action in Normal Subjects. Br. J. Audiol., 7: 105.

6. Colletti, V. (1974): Some Stapedius Reflex Parameters in Normal and Pathological Conditions. J. Laryngol. Otol., 88: 127:

7. Dallos, P. (1964): Dynamics of the Acoustic Reflex: Phenomenological Aspects. J. Acoust. Soc. Amer, 36, 2175.

8. Dix, M., Hallpike, C., and Hood, J. (1948): Observations upon the Loudness Recruitment Phenomenon with Special Reference to the Differential Diagnosis of Disorders of the Internal Ear and the Vllth Nerve. J. Laryngol. Otol., 62: 671.

9. Hirsh, I., Palva, T., and Goodman, A. (1954): Difference Limen and Recruitment. Arch. Otolaryngol., 60: 525. 
10. Jerger, J., Jerger, S., Maulding, L. (1972): Studies in Impedance Audiometry: I. Normal and Sensorineural Ears. Arch. Otolaryngol., 96, 513 .

11. Jerger, S., Jerger, J., Mauldin, L. (1974): Studies in Impedance Audiometry: II. Children Less than Six Years Old. Arch. Otolaryngol., 96: 513.

12. Metz, O. (1952): Threshold of Reflex Contractions of Muscles of the Middle Ear and Recruitment of Loudness. Arch. Otolaryngol., 55: 536 .

13. Møller, A. (1977): Function of the Middle Ear. Reprint from Handbook of Sensory Physiology, Keidel, W., and Neff, W. (Eds.) Springer-Verlag, pp. 492-516, Berlin, 1974. Presented at 1st Amplaid International Impedance Meeting, Milan.

14. Møller, A. (1977): The Acoustic Middle Ear Muscle Reflex. Reprint from Handbook of Sensory Physiology. Keidel, W. and Neff, W. (Eds.) pp. 520-544, Springer-Verlag, Berlin, 1974. Presented at 1st Aplaid International Impedance Meeting, Milan.

15. McCandless, G. (1975): Future Directions. In: Handbook of Clinical Impedance Audiometry, Jerger, J., (Ed.) Ch. 8., American Electromedics Corporation. Morgan Press, NY.

16. Peterson, J. and Liden, G. (1972): Some Static Characteristics of the Stapedius Muscle Reflex. Audiology, 11: 97.

17. Ross, S. (1968): On the Relation between the Acoustic Reflex and Loudness. J. Acoust. Soc. Amer., 43: 768.

18. Sheehy, J. and Inzer, B. (1976): Reflex Decay in Brainstem Lesions: Acoustic Reflex Test in Neuro-Otologic Diagnosis. Arch. Otolaryngol., 102: 647.

19. Stephens, S., Blegvad, B. and Krogh, H. (1977): The value of some suprathreshold auditory measures. Scand. Audiol., 6, (4): 213.

20. Zakrisson, J. E. and Borg, E. (1974): Stapedius Reflex and Auditory Fatigue. Audiology., 13: 231. 


\section{Advertisement}

\section{BINAURAL HEARING}

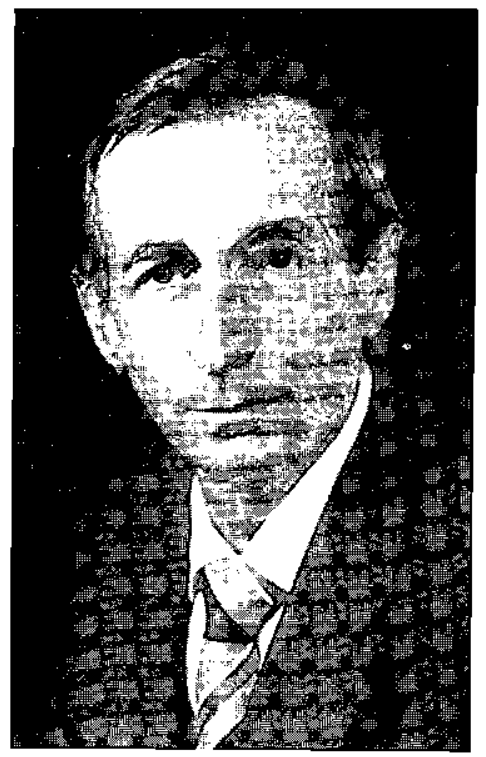

Mr. D. A. Smith

Today we can provide miniature hearing aids individually made to fit entirely into the ear with each hearing aid tailored to suit the individual hearing loss. There are hearing aids with automatic volume control, television attachments, telephone devices, acoustic filters and a host of technical innovations to improve performance.

With all these facilities available it is sad to think that most hearing aid users cannot enjoy truly relaxed hearing because of one simple fact - we are trying to make one ear do the job of two ears.

Nature has provided us with two ears for a very good reason. Anyone with normal hearing can experience the problems of a hearing aid user by simply blocking one ear in a group conversation - suddenly it becomes impossible to separate the voices.

The time has come to face some common sense facts. No-one with deficient eyesight wears a monocle anymore - or buys a spectacle with only one lens. Yet we allow people to wear one hearing aid and pretend the other ear doesn't exist.

Binaural (two ear) hearing aid fittings are not new. When they have been used they are extremely successful and people who have worn two hearing aids enjoy a quality of hearing comparable to normal hearing.

Why should this be so? Well, in the first place, with two hearing aids only half the sound power is needed for each ear. This means that loud sounds cause much less discomfort.

Secondly, because of the "phase relations" of sounds arriving at the two ears at slightly different time intervals the brain is able to "focus" subconsciously on desired sounds while ignoring unwanted background sounds.. This makes hearing possible in group conversation where everyone is talking at once.

Think also of the effect when crossing a busy street and not being able to tell where sounds are coming from. People with two normal ears react automatically to a noise from behind because two ears tell not only the direction of a sound but also the distance to the source of the sound. With a hearing aid on one ear it is a bit like crossing the road with one eye closed. 


\title{
Advertisement
}

Of course hearing aids can be expensive and it is not everyone who can pay for two hearing aids without some hardship. In order to encourage binaural fittings wherever appropriate we make special price arrangements where two hearing aids are required. For the adult hearing aid user best results can be obtained with two custom-made all-in-the-ear hearing aids.

The picture shows the DANAVOX MODEL 771 Hearing Aid with the microphone positioned where it should be - in the ear.

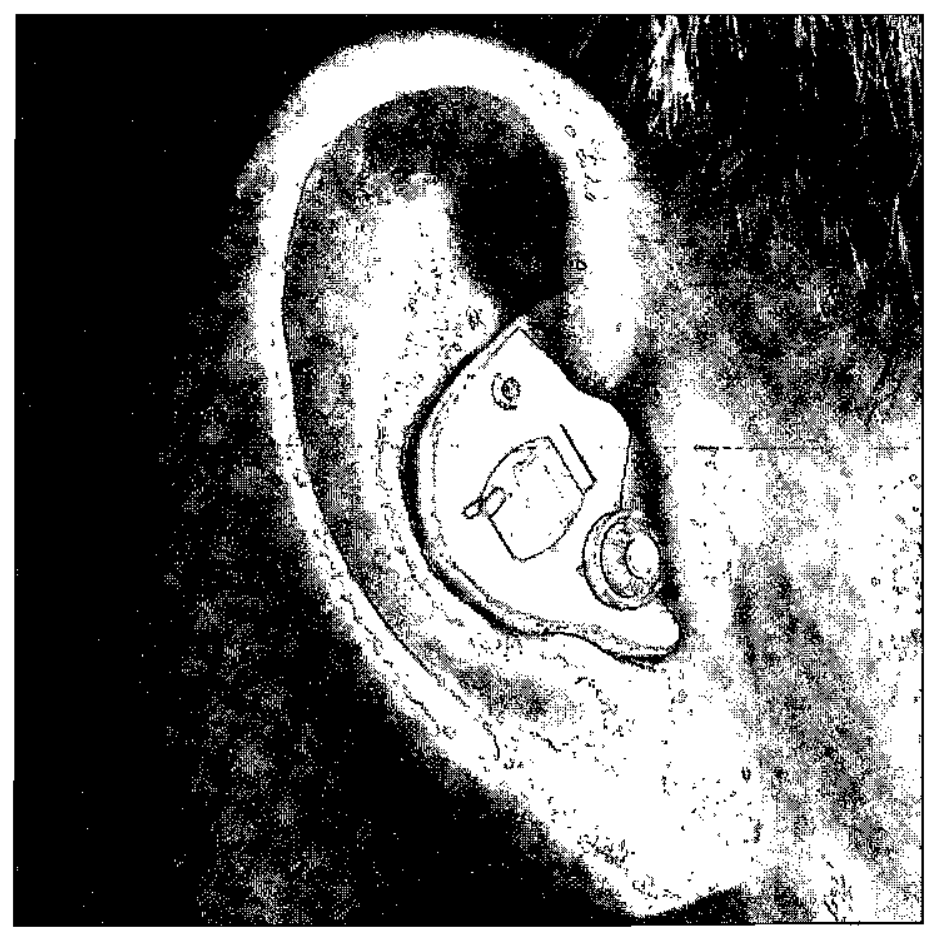

With an in the ear hearing aid the user does not have the feeling of wearing a hearing aid. The user can move around without thinking of the hearing aid falling off or being damaged by sudden shocks.

\section{ACOUSTIMED HEARING SERVICES}

\author{
315 Bosman Buildings \\ Cor. Eloff and Bree Streets \\ Johannesburg \\ Telephone (Head-Office) 37-2977
}

Agents for world renowned DANAVOX hearing aids 